Research Article

\title{
Dynamic Lever Arm Error Compensation of POS Used for Airborne Earth Observation
}

\author{
Lu Zhaoxing $\mathbb{D}^{1,2}$ Fang Jiancheng, ${ }^{2}$ Gong Xiaolin $\mathbb{D}^{2},{ }^{2}$ Li Jianli $\mathbb{D},{ }^{2}$ Wang Shicheng, \\ and Wang Yun' \\ ${ }^{1}$ Xi'an Institute of Hi-tech, Xi'an 710025, China \\ ${ }^{2}$ School of Instrument Science and Opto-Electronic Engineering, Beijing University of Aeronautics and Astronautics, \\ Beijing 100191, China
}

Correspondence should be addressed to Gong Xiaolin; gongxiaolin@buaa.edu.cn

Received 12 July 2017; Revised 31 January 2018; Accepted 12 March 2018; Published 9 May 2018

Academic Editor: Christopher J. Damaren

Copyright (c) 2018 Lu Zhaoxing et al. This is an open access article distributed under the Creative Commons Attribution License, which permits unrestricted use, distribution, and reproduction in any medium, provided the original work is properly cited.

\begin{abstract}
The position and orientation system (POS) is widely applied in airborne Earth observation, which integrates the strapdown inertial navigation system (SINS) and global positioning system (GPS) to provide high-accuracy position, velocity, and attitude information for remote sensing motion compensation. However, for keeping the appointed direction of remote sensing load, the inertial measurement unit (IMU) and remote sensing load will be driven to sweep by the servo machine. The lever arms among IMU, GPS, and remote sensing load will be time varying, and their influence on the measurement accuracy of POS is serious. To solve the problem, a dynamic lever arm error compensation method is proposed, which contains the first-level lever arm error compensations between IMU and GPS and the second-level lever arm error compensation between POS and remote sensing load. The flight experiment results show that the proposed method can effectively compensate the dynamic lever arm error and achieve high measurement accuracy for POS.
\end{abstract}

\section{Introduction}

Airborne Earth observation is a kind of high technology which makes the aircraft as the platform and uses remote sensing load to acquire a wide-range, high-accurate, and multilayered space-time information of global surface and deep Earth $[1,2]$. The ideal motion for precise airborne Earth observation is moving along a straight line with constant speed. However, the aircraft will inevitably deviate remote sensing load from the ideal motion trajectory due to the effects of gust, air turbulence, and the error of flight control. The position and orientation system (POS) is becoming crucial as an important way for remote sensing motion compensation [3-5]. POS is a dedicated strapdown inertial navigation system- (SINS-)/global positioning system- (GPS-) integrated system and can provide navigation information with excellent short-term accuracy and long-term stable accuracy characters, which gather the advantages of both SINS and GPS $[6,7]$.
As a multisensory system, POS is composed of inertial measurement units (IMUs) and global positioning system and needs to transfer the solutions to the measuring center of the remote sensing load. There exist some spatial differences among sensors. It makes the sensed motion information different from each other, which is called the lever arm effect. Without compensation, the lever arm effect will result in some serious measurement errors [8]. Over the past few years, many researches have been carried out to reduce the lever arm errors. The mechanization and compensation methods of the lever arm between IMU and GPS are analyzed in $[9,10]$. In [11], multilevel lever arm errors have been analyzed and compensated, including the inner lever arm caused by the displacement of the sensing center of an accelerometer from the center of inertial sensing assembly, the first-level lever arm between IMU and GPS, and the second-level lever arm between POS and remote sensing load. However, the direct calibration of lever arm is not always available. In [12], the lever arm error is extended 
to be a state variable of the Kalman filter, and the observability properties are studied with a control-theoretic approach, which indicates that changes in angular velocity enhance the lever arm estimate and both the motions of translation and constant angular velocity have no influence on the estimation of the lever arm. In [13], both numerical and experimental studies on the estimation of the lever arm are presented. Based on the observability analysis, the estimation precision in different stages has been analyzed in [14], and smoothing methods including Rauch-TungStriebel smoother and two-filter smoother are developed for precise lever arm estimation. Besides, the lever arm between the IMU and odometer is also taken into account for the land-vehicle navigation system in [15]. The lever arm between the Locata antenna and IMU is compensated for the Locata/SINS-integrated system in [16]. In the application of transfer alignment, the lever arm effects among master IMU and slave IMUs are analyzed and compensated in [17-19].

All above methods deal with the rigid lever arms. However, in the imaging process of airborne Earth observation, the appointed direction of remote sensing load is adjusted in real time in order to meet specific imaging needs. Consequently, the spatial relationship between IMU, GPS, and remote sensing load will change, which is named the dynamic lever arm effect. In $[20,21]$, the first-level dynamic lever arm between GPS and IMU caused by an inertially stabilized platform has been analyzed and compensated. For the second-level lever arm between POS and remote sensing load, there exist the installation angle errors, and the relative attitude between POS and remote sensing load will change with the rotation of remote sensing load. So the compensation method in $[20,21]$ is not suitable for the second-level dynamic lever arm. To solve this problem, a new algorithm which tackles the problem of not only the first-level dynamic lever arm but also the second-level dynamic lever arm for airborne Earth observation is proposed in the paper.

The paper is organized as follows. The conventional rigid lever arm error compensation method is presented in Section 2. The principle of both the first- and the secondlevel dynamic lever arm error compensation methods is derived in detail in Section 3. In Section 4, the experiment data of two flights is utilized to demonstrate the effectiveness of the proposed algorithm. Finally, Section 5 concludes the paper.

\section{Modeling and Compensation of Rigid Lever Arm Error}

The multilevel rigid lever arm mechanism is shown in Figure 1. It describes the relative spatial relation of various sensors including IMU, GPS, and imaging sensor. The firstlevel lever arm vector $\mathbf{l}_{\mathrm{I}}^{\mathrm{b}}$ refers to the spatial difference between the measuring centers of IMU and GPS in the IMU body frame, and the subscript $\mathrm{b}$ denotes the IMU body frame (b frame). The second-level lever arm vector $l_{I I}^{b}$ refers to the spatial difference between the measuring centers of the imaging sensor and IMU in the $b$ frame. The IMU cannot directly integrate with GPS because of $\mathrm{l}_{\mathrm{I}}^{\mathrm{b}}$, and the motion parameters of POS cannot be directly used for remote sensing load because of $\mathbf{l}_{\mathrm{II}}^{\mathrm{b}} \cdot \mathbf{l}_{\mathrm{I}}^{\mathrm{b}}$ and $\mathbf{l}_{\mathrm{II}}^{\mathrm{b}}$ can be calibrated by the total station after the installation of the system, which can be expressed as $\mathbf{l}_{\mathrm{I}}^{\mathrm{b}}=\left[x_{\mathrm{I}} y_{\mathrm{I}} z_{\mathrm{I}}\right]^{T}$ and $\mathbf{l}_{\mathrm{II}}^{\mathrm{b}}=\left[\begin{array}{ll}x_{\mathrm{II}} & y_{\mathrm{II}} z_{\mathrm{II}}\end{array}\right]^{T}$, respectively.

2.1. Modeling and Compensation of First-Level Rigid Lever Arm Error. By compensating the first-level rigid lever arm error, the position and velocity measured by GPS can be directly integrated with SINS. The position difference vector $\delta \mathbf{P}_{\mathrm{I}}^{\mathrm{n}}(t)$ caused by $\mathbf{l}_{\mathrm{I}}^{\mathrm{b}}$ in the navigation frame ( $\mathrm{n}$ frame) can be expressed as

$$
\delta \mathbf{P}_{\mathrm{I}}^{\mathrm{n}}(t)=\mathbf{C}_{\mathrm{b}}^{\mathrm{n}}(t) \mathbf{l}_{\mathrm{I}}^{\mathrm{b}}
$$

where $C_{b}^{n}(t)$ is the transformation matrix from the $b$ frame to the $\mathrm{n}$ frame, which can be calculated by three Euler angles, heading $\varphi(t)$, pitch $\theta(t)$, and roll $\gamma(t)$, and $\mathbf{C}_{\mathrm{b}}^{\mathrm{n}}(t)=$ $\left[\mathbf{C}_{\mathrm{n}}^{\mathrm{b}}(t)\right]^{T}=\left[\mathbf{C}_{\mathrm{n}}^{\mathrm{b}}(t)\right]^{-1}$. With the position compensation, the position vector $\mathbf{P}_{\mathrm{G}}^{\mathrm{n}}(t)$ measured by GPS can be transferred to the measuring center of IMU in the $\mathrm{n}$ frame, which can be expressed as

$$
\mathbf{P}_{\mathrm{IG}}^{\mathrm{n}}(t)=\mathbf{P}_{\mathrm{G}}^{\mathrm{n}}(t)+\mathbf{A}(t) \delta \mathbf{P}_{\mathrm{I}}^{\mathrm{n}}(t)
$$

where $\mathbf{A}(t)$ represents the matrix which can transform the position vector in the $\mathrm{n}$ frame to the Earth frame (e frame) and can be expressed as

$$
\mathbf{A}(t)=\left[\begin{array}{ccc}
\frac{1}{R_{\mathrm{M}}(t)+H_{\mathrm{p}}(t)} & 0 & 0 \\
0 & \frac{\sec L_{\mathrm{p}}(t)}{R_{\mathrm{N}}(t)+H_{\mathrm{p}}(t)} & 0 \\
0 & 0 & 1
\end{array}\right],
$$

where $L_{\mathrm{p}}(t)$ and $H_{\mathrm{p}}(t)$, respectively, represent the latitude and altitude measured by POS, $R_{\mathrm{M}}$ and $R_{\mathrm{N}}$ represent the main curvature radiuses along the meridian and the vertical plane of the meridian, respectively.

According to the derivation of (1), the velocity difference vector $\delta \mathbf{V}_{\mathrm{I}}^{\mathrm{n}}$ caused by $\mathbf{l}_{\mathrm{I}}^{\mathrm{b}}$ in the $\mathrm{n}$ frame can be written as

$$
\delta \mathbf{V}_{\mathrm{I}}^{\mathrm{n}}=\dot{\mathbf{C}}_{\mathrm{b}}^{\mathrm{n}}(t) \mathbf{l}_{\mathrm{I}}^{\mathrm{b}}=\mathbf{C}_{\mathrm{b}}^{\mathrm{n}}(t)\left[\boldsymbol{\omega}_{\mathrm{nb}}^{\mathrm{b}}(t) \times \mathbf{l}_{\mathrm{I}}^{\mathrm{b}}\right],
$$

where $\omega_{\mathrm{nb}}^{\mathrm{b}}(t)$ is the angular velocity vector of the $\mathrm{b}$ frame with respect to the $\mathrm{n}$ frame denoted in the $\mathrm{b}$ frame and can be calculated as

$$
\boldsymbol{\omega}_{\mathrm{nb}}^{\mathrm{b}}(t)=\boldsymbol{\omega}_{\mathrm{ib}}^{\mathrm{b}}(t)-\boldsymbol{\omega}_{\mathrm{in}}^{\mathrm{b}}(t)=\boldsymbol{\omega}_{\mathrm{ib}}^{\mathrm{b}}(t)-\mathrm{C}_{\mathrm{n}}^{\mathrm{b}}(t)\left[\boldsymbol{\omega}_{\mathrm{ie}}^{\mathrm{n}}(t)+\boldsymbol{\omega}_{\mathrm{en}}^{\mathrm{n}}(t)\right],
$$

where $\omega_{\mathrm{ib}}^{\mathrm{b}}(t)$ is the angular velocity vector of the $\mathrm{b}$ frame with respect to the inertial frame (i frame) denoted in the $b$ frame and can be directly measured by a gyroscope. $\omega_{\mathrm{ie}}^{\mathrm{n}}(t)$ is the angular velocity of the e frame with respect to 


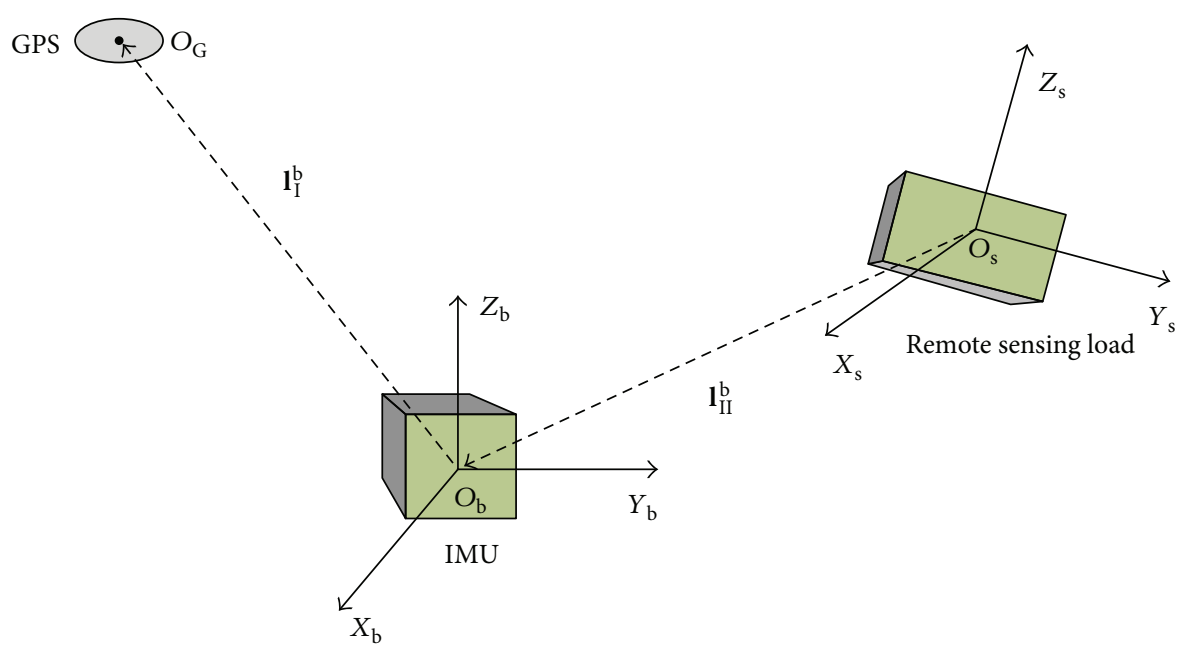

FIGURE 1: The multilevel rigid lever arm mechanism.

the $\mathrm{i}$ frame denoted in the $\mathrm{n}$ frame, which can be calculated by

$$
\begin{aligned}
\boldsymbol{\omega}_{\mathrm{ie}}^{\mathrm{n}}(t)= & \mathrm{C}_{\mathrm{e}}^{\mathrm{n}}(t) \cdot \boldsymbol{\omega}_{\mathrm{ie}}^{\mathrm{e}} \\
= & {\left[\begin{array}{ccc}
-\sin \lambda_{\mathrm{p}}(t) & \cos \lambda_{\mathrm{p}}(t) & 0 \\
-\sin L_{\mathrm{p}}(t) \cos \lambda_{\mathrm{p}}(t) & -\sin L_{\mathrm{p}}(t) \sin \lambda_{\mathrm{p}}(t) & \cos L_{\mathrm{p}}(t) \\
\cos L_{\mathrm{p}}(t) \cos \lambda_{\mathrm{p}}(t) & \cos L_{\mathrm{p}}(t) \sin \lambda_{\mathrm{p}}(t) & \sin L_{\mathrm{p}}(t)
\end{array}\right] } \\
& \cdot\left[\begin{array}{c}
0 \\
0 \\
\omega_{\mathrm{ie}}
\end{array}\right],
\end{aligned}
$$

where $\omega_{\text {ie }}$ is the rotation rate of the Earth. $\omega_{\mathrm{en}}^{\mathrm{n}}$ is the angular rate vector of the $\mathrm{n}$ frame with respect to the e frame expressed in the $\mathrm{n}$ frame, which can be calculated as

$$
\boldsymbol{\omega}_{\mathrm{en}}^{\mathrm{n}}(t)=\left[\frac{V_{\mathrm{pN}}(t)}{R_{\mathrm{M}}(t)+H_{\mathrm{p}}(t)} \frac{V_{\mathrm{pE}}(t)}{R_{\mathrm{N}}(t)+H_{\mathrm{p}}(t)} \frac{V_{\mathrm{pE}}(t) \tan L_{\mathrm{p}}(t)}{R_{\mathrm{N}}(t)+H_{\mathrm{p}}(t)}\right] \text {, }
$$

where $V_{\mathrm{pE}}(t)$ and $V_{\mathrm{pN}}(t)$ are the velocities measured by POS in the east and north axes, respectively.

With the velocity compensation, the velocity vector $\mathbf{V}_{\mathrm{G}}^{\mathrm{n}}(t)$ measured by GPS can be transferred to the measuring center of IMU in the $\mathrm{n}$ frame, which can be expressed as

$$
\mathbf{V}_{\mathrm{IG}}^{\mathrm{n}}(t)=\mathbf{V}_{\mathrm{G}}^{\mathrm{n}}(t)+\delta \mathbf{V}_{\mathrm{I}}^{\mathrm{n}}(t) .
$$

2.2. Modeling and Compensation of Second-Level Rigid Lever Arm Error. With the second-level rigid lever arm error compensation, the measurement solutions of POS can be transferred to the measuring center of the imaging sensor. The position difference vector $\delta \mathbf{P}_{\mathrm{II}}^{\mathrm{n}}(t)$ caused by $\mathbf{l}_{\mathrm{II}}^{\mathrm{b}}$ in the $\mathrm{n}$ frame can be expressed as

$$
\delta \mathbf{P}_{\mathrm{II}}^{\mathrm{n}}(t)=\mathbf{C}_{\mathrm{b}}^{\mathrm{n}}(t) \mathbf{l}_{\mathrm{II}}^{\mathrm{b}}
$$

With the position compensation, the position vector $\mathbf{P}_{\mathrm{sp}}^{\mathrm{n}}$ $(t)$ compensated by $\delta \mathbf{P}_{\mathrm{II}}^{\mathrm{n}}(t)$ can be expressed as

$$
\mathbf{P}_{\mathrm{sp}}^{\mathrm{n}}(t)=\mathbf{P}_{\mathrm{p}}^{\mathrm{n}}(t)+\mathbf{A}(t) \delta \mathbf{P}_{\mathrm{II}}^{\mathrm{n}}(t)=\mathbf{P}_{\mathrm{p}}^{\mathrm{n}}(t)+\mathbf{A}(t) \mathbf{C}_{\mathrm{b}}^{\mathrm{n}} \mathbf{l}_{\mathrm{II}}^{\mathrm{b}} .
$$

According to the derivation of (9), the velocity difference vector $\delta \mathbf{V}_{\mathrm{II}}^{\mathrm{n}}$ caused by $\mathbf{l}_{\mathrm{II}}^{\mathrm{b}}$ in the $\mathrm{n}$ frame can be written as

$$
\delta \mathbf{V}_{\mathrm{II}}^{\mathrm{n}}(t)=\mathbf{C}_{\mathrm{b}}^{\mathrm{n}}(t) \mathbf{l}_{\mathrm{II}}^{\mathrm{b}}=\mathbf{C}_{\mathrm{b}}^{\mathrm{n}}(t)\left[\boldsymbol{\omega}_{\mathrm{nb}}^{\mathrm{b}}(t) \times \mathbf{l}_{\mathrm{II}}^{\mathrm{b}}\right] .
$$

Using (11), the velocity vector $\mathbf{V}_{\mathrm{sp}}^{\mathrm{n}}(t)$ of the measuring center of remote sensing load compensated by $\delta \mathbf{V}_{\mathrm{II}}^{\mathrm{n}}(t)$ in the $\mathrm{n}$ frame can be written as

$$
\mathbf{V}_{\mathrm{sp}}^{\mathrm{n}}(t)=\mathbf{V}_{\mathrm{p}}^{\mathrm{n}}(t)+\delta \mathbf{V}_{\mathrm{II}}^{\mathrm{n}}(t)=\mathbf{V}_{\mathrm{p}}^{\mathrm{n}}(t)+\mathbf{C}_{\mathrm{b}}^{\mathrm{n}}(t)\left[\boldsymbol{\omega}_{\mathrm{nb}}^{\mathrm{b}}(t) \times \mathbf{l}_{\mathrm{II}}^{\mathrm{b}}\right] .
$$

Considering the installation angle error, the transformation matrix $\mathbf{C}_{\mathrm{n}}^{\mathrm{s}}(t)$ from the $\mathrm{n}$ frame to the remote sensing load frame (s frame) can be expressed as

$$
\mathbf{C}_{\mathrm{n}}^{\mathrm{s}}(t)=\mathbf{C}_{\mathrm{b}}^{\mathrm{s}} \mathbf{C}_{\mathrm{n}}^{\mathrm{b}}(t),
$$

where $\mathrm{C}_{\mathrm{b}}^{\mathrm{s}}$ is the invariable transformation matrix from the $\mathrm{b}$ frame to the s frame and can be calculated during the initial calibration, the expression of which is as follows:

$$
\begin{aligned}
\mathbf{C}_{\mathrm{b}}^{\mathrm{s}}= & {\left[\begin{array}{ccc}
\cos \vartheta_{z} & \sin \vartheta_{z} & 0 \\
-\sin \vartheta_{z} & \cos \vartheta_{z} & 0 \\
0 & 0 & 1
\end{array}\right]\left[\begin{array}{ccc}
\cos \vartheta_{y} & 0 & -\sin \vartheta_{y} \\
0 & 1 & 0 \\
\sin \vartheta_{y} & 0 & \cos \vartheta_{y}
\end{array}\right] } \\
& \cdot\left[\begin{array}{ccc}
1 & 0 & 0 \\
0 & \cos \vartheta_{x} & \sin \vartheta_{x} \\
0 & -\sin \vartheta_{x} & \cos \vartheta_{x}
\end{array}\right],
\end{aligned}
$$


where $\vartheta_{x}, \vartheta_{y}$, and $\vartheta_{z}$ are the three rotary Euler angles from the $\mathrm{b}$ frame to the $\mathrm{s}$ frame in turn along the $x, y$, and $z$ axes. Further, the heading, pitch, and roll of the remote sensing load can be calculated according to (14).

Remark 1. The laser total station is chosen for the initial calibration of $\vartheta_{x}, \vartheta_{y}$, and $\vartheta_{z}$. Firstly, the target points are attached to the referenced position of IMU and SAR, and the coordinates of each point can be calibrated by the laser total station. Secondly, three axial unit vectors of both IMU and SAR can be calculated based on the calibration information of the target points. Thirdly, the installation error angles between IMU and SAR can be calculated according to the three axial unit vectors.

\section{Modeling and Compensation of Dynamic Lever Arm Error}

In some special imaging process of airborne Earth observation, the appointed direction of remote sensing load will be adjusted in order to evidently improve imaging efficiency and accuracy. Consequently, the relative spatial relationships among sensors vary in real time, which is called the dynamic lever arm. The dynamic lever arm can be divided into two kinds. One kind is named the first-level dynamic lever arm, which is shown in Figure 2. In this case, the remote sensing load fixed to IMU can be driven by the servo machine to sweep along the rotary axis, which changes the relative spatial vector between GPS and IMU. This kind of installation allows the IMU to directly measure the motion parameters of the remote sensing load, including the influence of random vibration on the remote sensing load.

The other kind is named the second-level dynamic lever arm, which is shown in Figure 3. In this case, the IMU and GPS are directly assembled onto the plane body and are close to the servo machine. The rotation of the remote sensing load will change the relative spatial vector between the IMU and remote sensing load. This kind of installation makes the POS a universal measuring instrument, which can be used for various kinds of remote sensing loads such as CCD cameras and SAR.

3.1. Modeling and Compensation of First-Level Dynamic Lever Arm Error. As shown in Figure 2, $\mathbf{L}_{\text {Is }}$ refers to the rigid lever arm between the GPS measuring center and the rotary axis center. $\mathbf{L}_{\text {Ir }}$ is the rotation lever arm between the rotary axis center and the measuring center of IMU. After system installation, a high-precision laser total station can be used to calibrate the rigid lever arm $\mathbf{L}_{\mathrm{Is}}^{\mathrm{b}_{0}}$ and the rotation lever $\operatorname{arm} \mathbf{L}_{\text {Ir }}^{b_{0}}$ in the initial IMU body frame ( $b_{0}$ frame). The transformation matrix $\mathbf{C}_{\mathrm{b}_{0}}^{\mathrm{R}_{0}}\left(t_{0}\right)$ from the $b$ frame to the initial rotary frame ( $R_{0}$ frame) can also be calculated.

The servo machine turns along the rotary axis in real time. At moment $t$, the output angle $\sigma(t)$ of the photoelectric encoder can be measured, and the transformation matrix from the $\mathrm{R}_{0}$ frame to the $\mathrm{R}$ frame can be given:

$$
\mathbf{C}_{\mathrm{R}_{0}}^{\mathrm{R}}(t)=\left[\begin{array}{ccc}
\cos \left[\sigma(t)-\sigma_{0}\right] & 0 & -\sin \left[\sigma(t)-\sigma_{0}\right] \\
0 & 1 & 0 \\
\sin \left[\sigma(t)-\sigma_{0}\right] & 0 & \cos \left[\sigma(t)-\sigma_{0}\right]
\end{array}\right] .
$$

As the $\mathrm{b}$ frame is fixed in the $\mathrm{R}$ frame, the transformation matrix $\mathrm{C}_{\mathrm{b}}^{\mathrm{R}}(t)$ from the $\mathrm{b}$ frame to the $\mathrm{R}$ frame is time invariant and can be expressed as

$$
\mathbf{C}_{\mathrm{b}}^{\mathrm{R}}(t)=\mathbf{C}_{\mathrm{b}_{0}}^{\mathrm{R}_{0}}\left(t_{0}\right) .
$$

3.1.1. Position Error Modeling and Compensation. The rigid lever $\operatorname{arm} \mathbf{L}_{\mathrm{Is}}^{\mathrm{b}}(t)$ can be calculated as

$$
\mathbf{L}_{\mathrm{Is}}^{\mathrm{b}}(t)=\mathbf{C}_{\mathrm{b}_{0}}^{\mathrm{b}}(t) \mathbf{L}_{\mathrm{Is}}^{\mathrm{b}_{0}}=\left[\mathbf{C}_{\mathrm{b}_{0}}^{\mathrm{R}_{0}}\left(t_{0}\right)\right]^{-1} \mathbf{C}_{\mathrm{R}_{0}}^{\mathrm{R}}(t) \mathbf{C}_{\mathrm{b}_{0}}^{\mathrm{R}_{0}}(t) \mathbf{L}_{\mathrm{Is}}^{\mathrm{b}_{0}} .
$$

As the rotation lever $\operatorname{arm} \mathbf{L}_{\mathrm{Ir}}$ is fixed in the $\mathrm{b}$ frame, it can be calculated at moment $t$ as

$$
\mathbf{L}_{\mathrm{Ir}}^{\mathrm{b}}(t)=\mathbf{L}_{\mathrm{Ir}}^{\mathrm{b}_{0}}
$$

According to (17) and (18), the position difference vector $\delta \mathbf{P}_{\mathrm{Id}}^{\mathrm{n}}(t)$ caused by the first-level dynamic lever arm in the $\mathrm{n}$ frame can be expressed as

$$
\begin{aligned}
\delta \mathbf{P}_{\mathrm{Id}}^{\mathrm{n}}(t)= & \mathbf{C}_{\mathrm{b}}^{\mathrm{n}}(t) \mathbf{L}_{\mathrm{I}}^{\mathrm{b}}(t)=\mathbf{C}_{\mathrm{b}}^{\mathrm{n}}(t)\left(\mathbf{C}_{\mathrm{b}_{0}}^{\mathrm{R}_{0}}\left(t_{0}\right)\right)^{-1} \mathbf{C}_{\mathrm{R}_{0}}^{\mathrm{R}}(t) \mathbf{C}_{\mathrm{b}_{0}}^{\mathrm{R}_{0}}(t) \mathbf{L}_{\mathrm{Is}}^{\mathrm{b}_{0}} \\
& +\mathbf{C}_{\mathrm{b}}^{\mathrm{n}}(t) \mathbf{L}_{\mathrm{Ir}}^{\mathrm{b}_{0}}
\end{aligned}
$$

With the position compensation, the position vector $\mathbf{P}_{\mathrm{G}}^{\mathrm{n}}$ $(t)$ measured by GPS can be transferred to the measuring center of IMU in the $\mathrm{n}$ frame, which can be expressed as

$$
\mathbf{P}_{\mathrm{IdG}}^{\mathrm{n}}(t)=\mathbf{P}_{\mathrm{G}}^{\mathrm{n}}(t)+\mathbf{A}(t) \delta \mathbf{P}_{\mathrm{Id}}^{\mathrm{n}}(t) .
$$

3.1.2. Velocity Error Modeling and Compensation. According to the derivation of (19), the velocity difference vector $\delta \mathbf{V}_{\mathrm{Id}}^{\mathrm{n}}$ caused by the first-level dynamic lever arm in the $\mathrm{n}$ frame can be written as

$$
\begin{aligned}
\delta \mathbf{V}_{\mathrm{Id}}^{\mathrm{n}}(t)= & \dot{\mathbf{C}}_{\mathrm{b}}^{\mathrm{n}}(t) \mathbf{L}_{\mathrm{I}}^{\mathrm{b}}(t)+\mathbf{C}_{\mathrm{b}}^{\mathrm{n}}(t) \dot{\mathbf{L}}_{\mathrm{I}}^{\mathrm{b}}(t) \\
= & \mathbf{C}_{\mathrm{b}}^{\mathrm{n}}(t)\left[\boldsymbol{\omega}_{\mathrm{nb}}^{\mathrm{b}}(t) \times \mathbf{L}_{\mathrm{I}}^{\mathrm{b}}(t)\right]+\mathbf{C}_{\mathrm{b}}^{\mathrm{n}}(t)\left[\dot{\boldsymbol{\sigma}}^{\mathrm{b}}(t) \times \mathbf{L}_{\mathrm{Ir}}^{\mathrm{b}}(t)\right] \\
= & \mathbf{C}_{\mathrm{b}}^{\mathrm{n}}(t)\left[\boldsymbol{\omega}_{\mathrm{nb}}^{\mathrm{b}}(t) \times \mathbf{L}_{\mathrm{I}}^{\mathrm{b}}(t)\right] \\
& +\mathbf{C}_{\mathrm{b}}^{\mathrm{n}}(t)\left\{\left[\left[\mathbf{C}_{\mathrm{b}_{0}}^{\mathrm{R}_{0}}\left(t_{0}\right)\right]^{-1} \dot{\boldsymbol{\sigma}}^{\mathrm{R}}(t)\right] \times \mathbf{L}_{\mathrm{Ir}}^{\mathrm{b}_{0}}\right\},
\end{aligned}
$$

where $\boldsymbol{\omega}_{\mathrm{nb}}^{\mathrm{b}}(t)$ can be calculated by (5) and $\dot{\boldsymbol{\sigma}}^{\mathrm{R}}(t)$ is the angular velocity vector of the $R$ frame with respect to the $R_{0}$ frame denoted in the $\mathrm{R}$ frame and can be calculated as

$$
\dot{\boldsymbol{\sigma}}^{\mathrm{R}}(t)=\left[\begin{array}{c}
0 \\
\frac{\sigma(t)-\sigma\left(t^{-}\right)}{t-t^{-}} \\
0
\end{array}\right],
$$




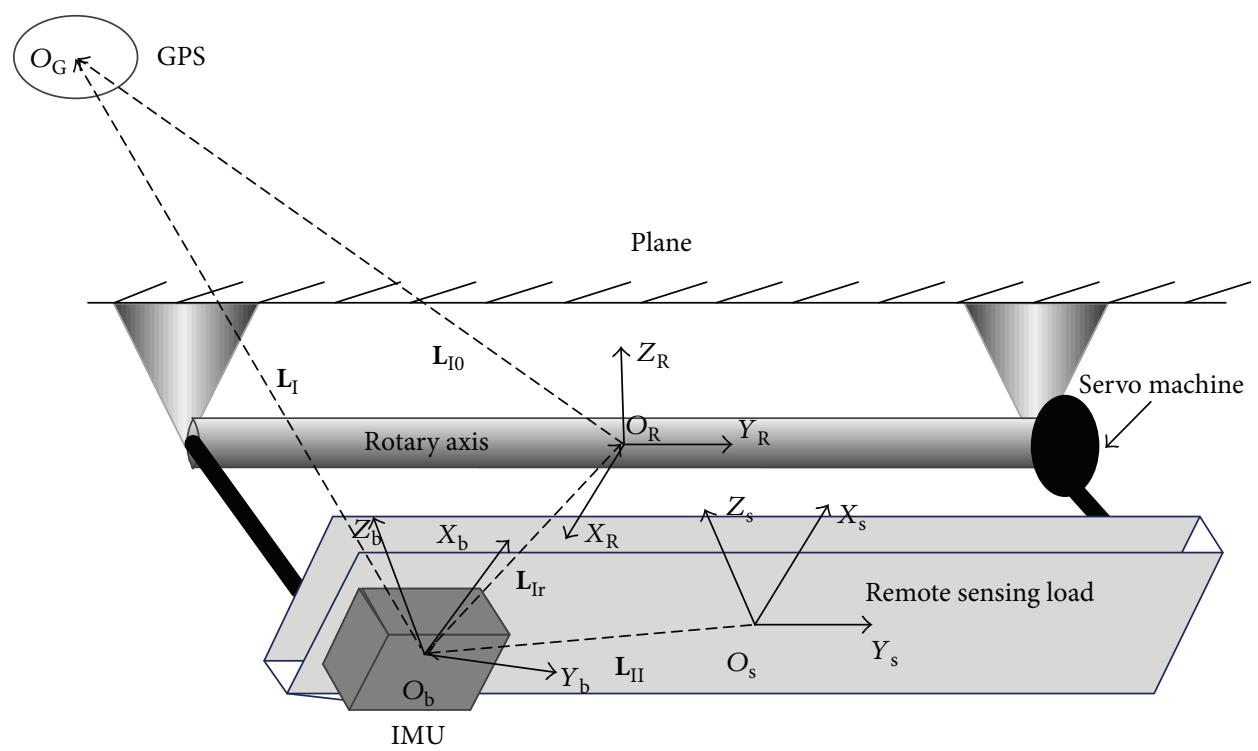

Figure 2: The first-level dynamic lever arm mechanism.

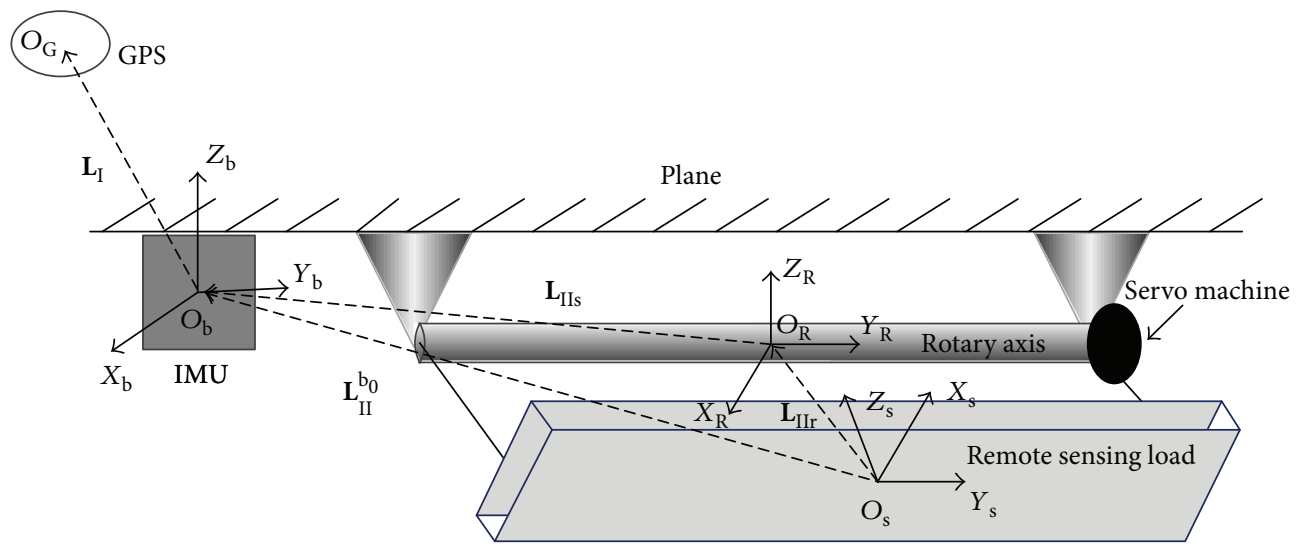

FIgURE 3: The second-level dynamic lever arm mechanism.

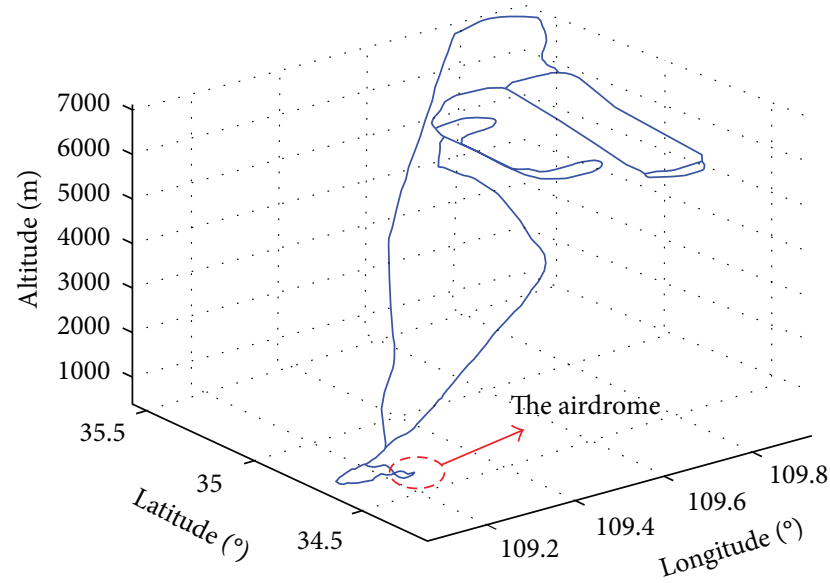

FIgURE 4: The flight trajectory of the experiment in Shaanxi Province, China, April 2017.

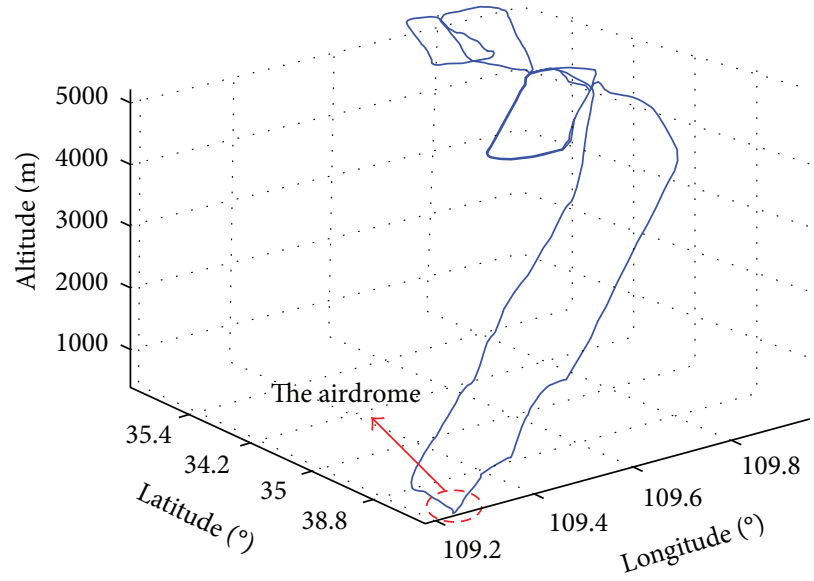

Figure 5: The flight trajectory of the experiment in Shaanxi Province, China, in March 2016. 
TABLE 1: Calibration result of the experiment system in Figure 4.

\begin{tabular}{|c|c|c|c|c|}
\hline & & $x$ & $y$ & $z$ \\
\hline \multirow{2}{*}{ First-level dynamic lever arm $\mathbf{L}_{\mathrm{I}}^{\mathrm{b}}(\mathrm{m})$} & Rigid lever $\operatorname{arm} \mathbf{L}_{\mathrm{Is}}^{\mathrm{b}}$ & 3.547 & -3.090 & 2.030 \\
\hline & Rotation lever $\operatorname{arm} \mathbf{L}_{\mathrm{Ir}}^{\mathrm{b}}$ & -0.117 & 0.512 & 0.042 \\
\hline Second-level rigid lever arm $\mathbf{L}_{\mathrm{II}}^{\mathrm{b}}(\mathrm{m})$ & & -0.288 & 0.526 & 0.180 \\
\hline Initial transformation matrix $\mathrm{C}_{\mathrm{b}_{0}}^{\mathrm{R}_{0}}$ & & & {$\left[\begin{array}{lll}1 & 0 & 0 \\
0 & 1 & 0 \\
0 & 0 & 1\end{array}\right]$} & \\
\hline Initial output angle $\sigma_{0}\left({ }^{\circ}\right)$ & & & 57.105 & \\
\hline
\end{tabular}

TABLE 2: Calibration result of the experiment system in Figure 5.

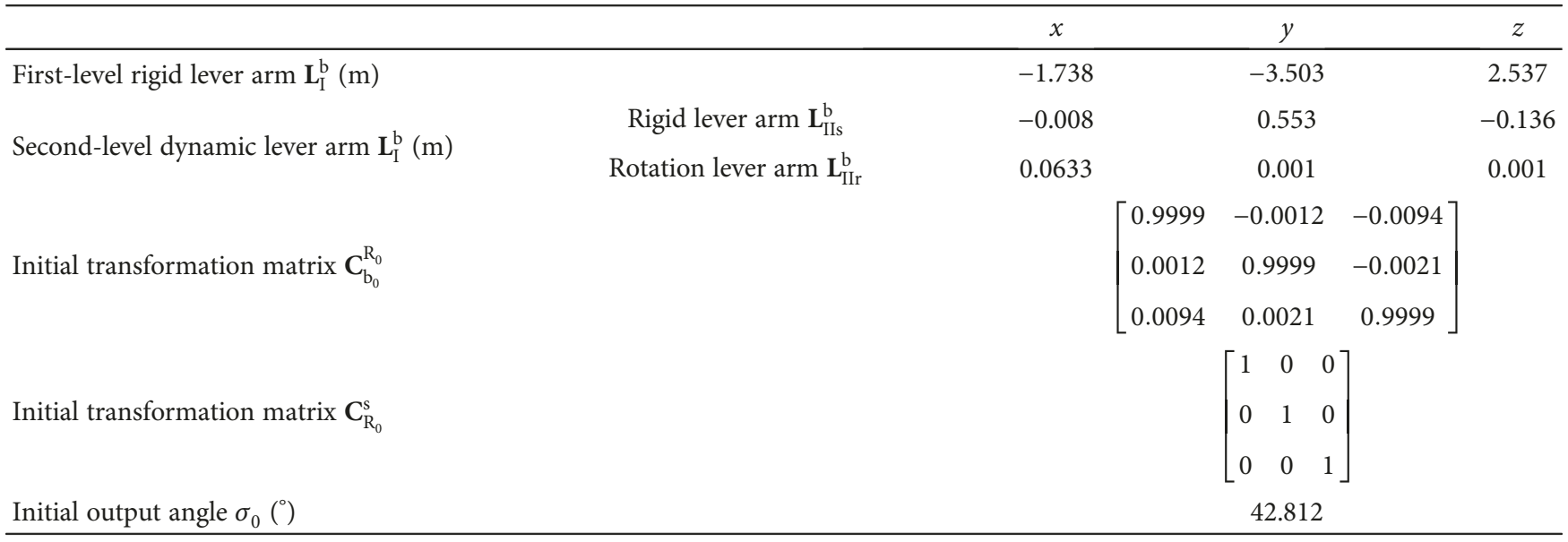

where $\sigma(t)$ and $\sigma\left(t^{-}\right)$, respectively, present the output angles of the photoelectric encoder in last update time $t$ and current update time $t^{-}$along the rotary axis of the servo machine. Since the differential coefficient has a noise amplification effect, the output angles $\sigma(t)$ and $\sigma\left(t^{-}\right)$should be well filtered. Otherwise, the noise error of angular acceleration is insufferable.

With the velocity compensation, the velocity vector $\mathbf{V}_{\mathrm{G}}^{\mathrm{n}}(t)$ measured by GPS can be transferred to the measuring center of IMU in the $\mathrm{n}$ frame, which can be expressed as

$$
\mathbf{V}_{\mathrm{IdG}}^{\mathrm{n}}(t)=\mathbf{V}_{\mathrm{G}}^{\mathrm{n}}(t)+\delta \mathbf{V}_{\mathrm{Id}}^{\mathrm{n}}(t)
$$

Remark 2. As POS is a nonlinear integrated system, nonlinear estimation algorithms such as the extended Kalman filter and unscented Kalman filter can be used for IMU/GPS integration, in which the measurement of GPS must be compensated as Section 3.1.

\subsection{Modeling and Compensation of Second-Level Dynamic} Lever Arm Error. As shown in Figure 3, $\mathbf{L}_{\mathrm{IIs}}$ refers to the rigid lever arm between the measuring center of IMU $O_{\mathrm{b}}$ and the rotary axis center $O_{\mathrm{R}}$ and $\mathrm{L}_{\mathrm{IIr}}$ is the rotation lever arm between the rotary axis center $O_{\mathrm{R}}$ and the measuring center of the remote sensing load $O_{s}$. After system

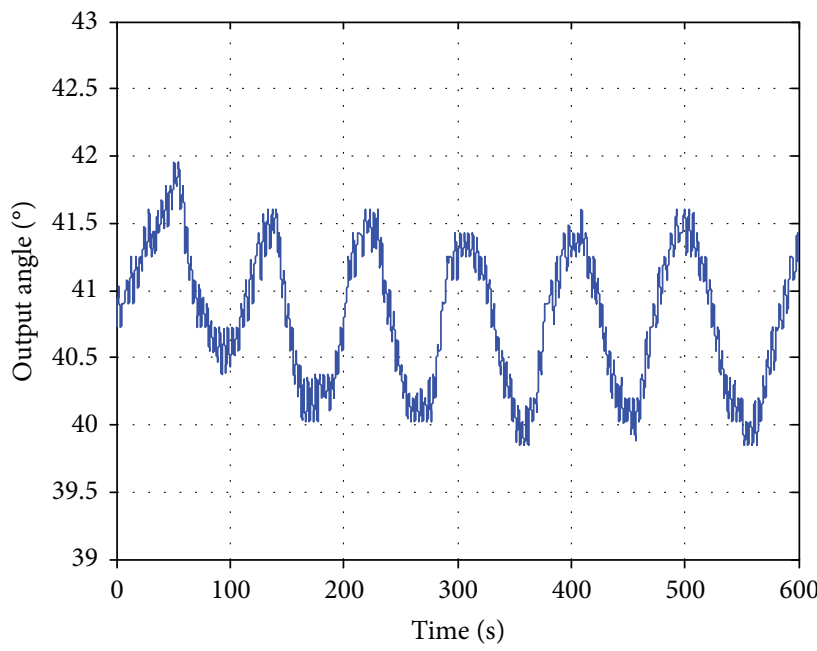

FIgURE 6: The output angles of the photoelectric encoder used in the experiment system in Figure 4.

installation, the rigid lever $\operatorname{arm} \mathbf{L}_{\mathrm{IIs}}^{\mathrm{b}_{0}}$ and the rotation lever $\operatorname{arm} \mathbf{L}_{\text {IIr }}^{b_{0}}$ can be calculated in the $b_{0}$ frame. The transformation matrix $\mathrm{C}_{\mathrm{b}}^{\mathrm{R}_{0}}\left(t_{0}\right)$ from the $\mathrm{b}$ frame to the $\mathrm{R}_{0}$ frame and the transformation matrix $\mathrm{C}_{\mathrm{R}_{0}}^{\mathrm{s}}\left(t_{0}\right)$ from the $\mathrm{R}_{0}$ frame 

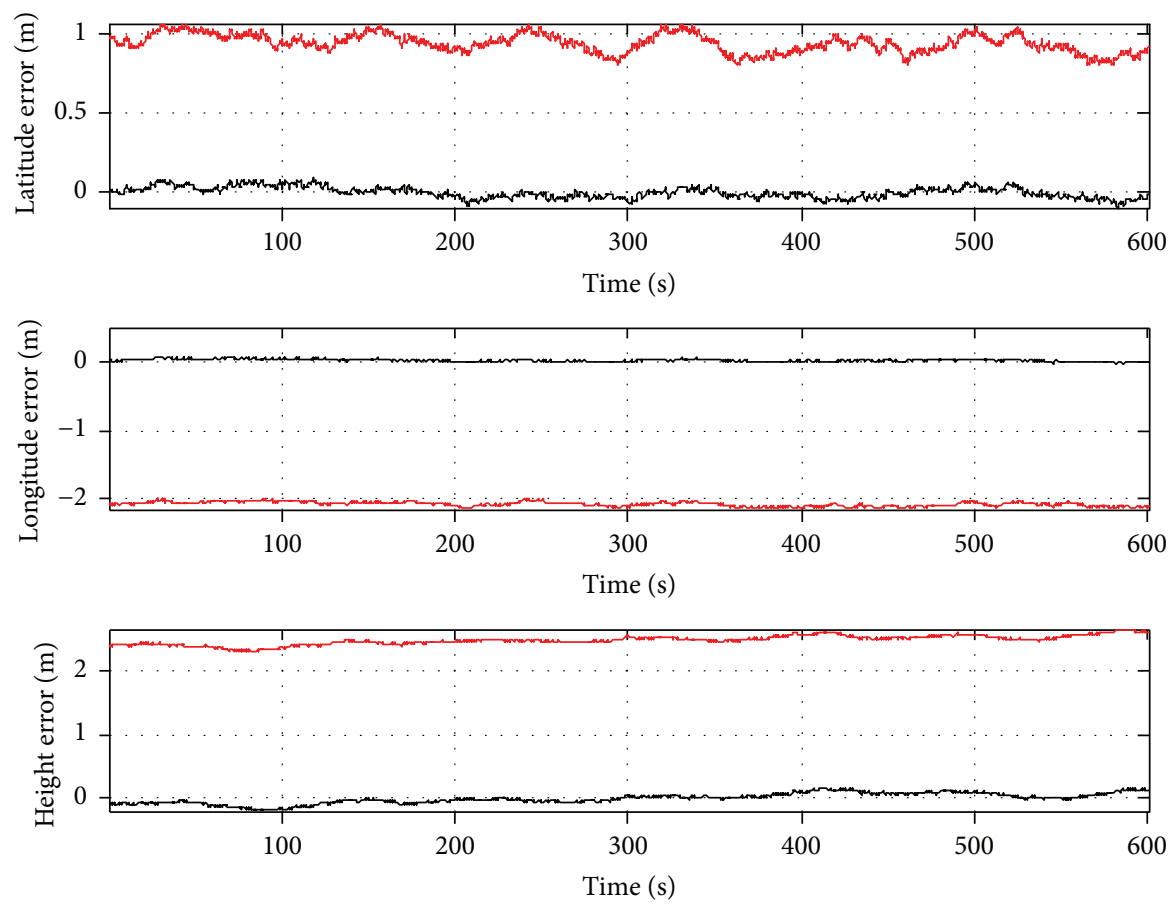

With rigid lever arm compensation

With dynamic lever arm compensation

Figure 7: Position error comparison of the first-level dynamic lever arm error compensation.

to the $\mathrm{s}$ frame can all be calibrated by a high-precision laser total station. The transformation matrix $\mathbf{C}_{\mathrm{R}}^{\mathrm{s}}$ from the $\mathrm{R}$ frame to the $\mathrm{s}$ frame and the transformation matrix $\mathrm{C}_{\mathrm{b}}^{\mathrm{R}_{0}}$ from the $\mathrm{b}$ frame to the $\mathrm{R}_{0}$ frame are time invariant, which can be expressed as

$$
\begin{aligned}
\mathbf{C}_{\mathrm{R}}^{\mathrm{s}}(t) & =\mathrm{C}_{\mathrm{R}_{0}}^{\mathrm{s}}\left(t_{0}\right), \\
\mathrm{C}_{\mathrm{b}}^{\mathrm{R}_{0}}(t) & =\mathrm{C}_{\mathrm{b}}^{\mathrm{R}_{0}}\left(t_{0}\right) .
\end{aligned}
$$

3.2.1. Position Error Modeling and Compensation. The rigid lever arm $\mathbf{L}_{\mathrm{IIs}}^{\mathrm{b}}(t)$ denoted in the $\mathrm{b}$ frame is time invariant and can be calculated as

$$
\mathbf{L}_{\mathrm{IIs}}^{\mathrm{b}}(t)=\mathbf{L}_{\mathrm{II}}^{\mathrm{b}_{0}} \text {. }
$$

The rotation lever arm $\mathbf{L}_{\mathrm{IIr}}$ is fixed in the $\mathrm{s}$ frame and is time invariant, which is denoted in the $s$ frame and expressed as

$$
\mathbf{L}_{\mathrm{IIr}}^{\mathrm{s}}(t)=\mathbf{L}_{\mathrm{IIr}}^{\mathrm{s}}\left(t_{0}\right)=\mathbf{C}_{\mathrm{R}_{0}}^{\mathrm{s}}\left(t_{0}\right) \mathbf{C}_{\mathrm{b}}^{\mathrm{R}_{0}}\left(t_{0}\right) \mathbf{L}_{\mathrm{IIr}}^{\mathrm{b}_{0}}
$$

Further, the rotation lever arm $\mathbf{L}_{\mathrm{IIr}}$ can be expressed in the $b$ frame as

$$
\begin{aligned}
\mathbf{L}_{\text {IIr }}^{\mathrm{b}}(t) & =\mathbf{C}_{\mathrm{R}_{0}}^{\mathrm{b}}(t) \mathbf{C}_{\mathrm{R}}^{\mathrm{R}_{0}}(t) \mathbf{C}_{\mathrm{s}}^{\mathrm{R}}(t) \mathbf{L}_{\mathrm{IIr}}^{\mathrm{s}}(t) \\
& =\left[\mathbf{C}_{\mathrm{b}}^{\mathrm{R}_{0}}\left(t_{0}\right)\right]^{-1} \mathbf{C}_{\mathrm{R}}^{\mathrm{R}_{0}}(t) \mathbf{C}_{\mathrm{b}}^{\mathrm{R}_{0}}\left(t_{0}\right) \mathbf{L}_{\text {IIr }}^{\mathrm{b}_{0}}
\end{aligned}
$$

According to (25) and (27), the position difference vector $\delta \mathbf{P}_{\text {IId }}^{\mathrm{n}}(t)$ caused by the second-level dynamic lever arm in the $\mathrm{n}$ frame can be expressed as

$$
\begin{aligned}
\delta \mathbf{P}_{\mathrm{IId}}^{\mathrm{n}}(t) & =\mathbf{C}_{\mathrm{b}}^{\mathrm{n}}(t) \mathbf{L}_{\mathrm{II}}^{\mathrm{b}}(t)=\mathbf{C}_{\mathrm{b}}^{\mathrm{n}}(t)\left[\mathbf{L}_{\mathrm{IIs}}^{\mathrm{b}}(t)+\mathbf{L}_{\mathrm{IIr}}^{\mathrm{b}}(t)\right] \\
& =\mathbf{C}_{\mathrm{b}}^{\mathrm{n}}(t)\left[\mathbf{C}_{\mathrm{b}}^{\mathrm{R}_{0}}\left(t_{0}\right)\right]^{-1} \mathbf{C}_{\mathrm{R}}^{\mathrm{R}_{0}}(t) \mathbf{C}_{\mathrm{b}}^{\mathrm{R}_{0}}\left(t_{0}\right) \mathbf{L}_{\mathrm{IIr}}^{\mathrm{b}_{0}}+\mathbf{C}_{\mathrm{b}}^{\mathrm{n}}(t) \mathbf{L}_{\mathrm{IIs}}^{\mathrm{b}_{0}} .
\end{aligned}
$$

With the position compensation of $\delta \mathbf{P}_{\text {IId }}^{\mathrm{n}}(t)$, the position vector $\mathbf{P}_{\mathrm{p}}^{\mathrm{n}}(t)$ measured by POS can be transferred to the measuring center of the remote sensing load in the $\mathrm{n}$ frame, which can be expressed as

$$
\mathbf{P}_{\mathrm{sp}}^{\mathrm{n}}(t)=\mathbf{P}_{\mathrm{p}}^{\mathrm{n}}(t)+\mathbf{A}(t) \delta \mathbf{P}_{\text {IId }}^{\mathrm{n}}(t) .
$$

3.2.2. Velocity Error Modeling and Compensation. According to the derivation of (28), the velocity difference vector $\delta \mathbf{V}_{\text {IId }}^{\mathrm{n}}$ caused by the second-level dynamic lever arm in the $\mathrm{n}$ frame can be written as

$$
\begin{aligned}
\delta \mathbf{V}_{\mathrm{II}}^{\mathrm{n}}(t)= & \dot{\mathbf{C}}_{\mathrm{b}}^{\mathrm{n}}(t) \mathbf{L}_{\mathrm{II}}^{\mathrm{b}}(t)+\mathbf{C}_{\mathrm{b}}^{\mathrm{n}}(t) \dot{\mathbf{L}}_{\mathrm{II}}^{\mathrm{b}}(t) \\
= & \mathbf{C}_{\mathrm{b}}^{\mathrm{n}}(t)\left[\boldsymbol{\omega}_{\mathrm{nb}}^{\mathrm{b}}(t) \times \mathbf{L}_{\mathrm{II}}^{\mathrm{b}}(t)\right]+\mathbf{C}_{\mathrm{b}}^{\mathrm{n}}(t)\left[\dot{\boldsymbol{\sigma}}^{\mathrm{b}}(t) \times \mathbf{L}_{\mathrm{IIr}}^{\mathrm{b}}(t)\right] \\
= & \mathbf{C}_{\mathrm{b}}^{\mathrm{n}}(t)\left[\boldsymbol{\omega}_{\mathrm{nb}}^{\mathrm{b}}(t) \times \mathbf{L}_{\mathrm{II}}^{\mathrm{b}}(t)\right] \\
& +\mathbf{C}_{\mathrm{b}}^{\mathrm{n}}(t)\left\{\left\{\left[\mathbf{C}_{\mathrm{b}}^{\mathrm{R}_{0}}(t)\right]^{-1} \mathbf{C}_{\mathrm{R}}^{\mathrm{R}_{0}}(t) \dot{\boldsymbol{\sigma}}^{\mathrm{R}}(t)\right\} \times \mathbf{L}_{\mathrm{IIr}}^{\mathrm{b}}(t)\right\},
\end{aligned}
$$



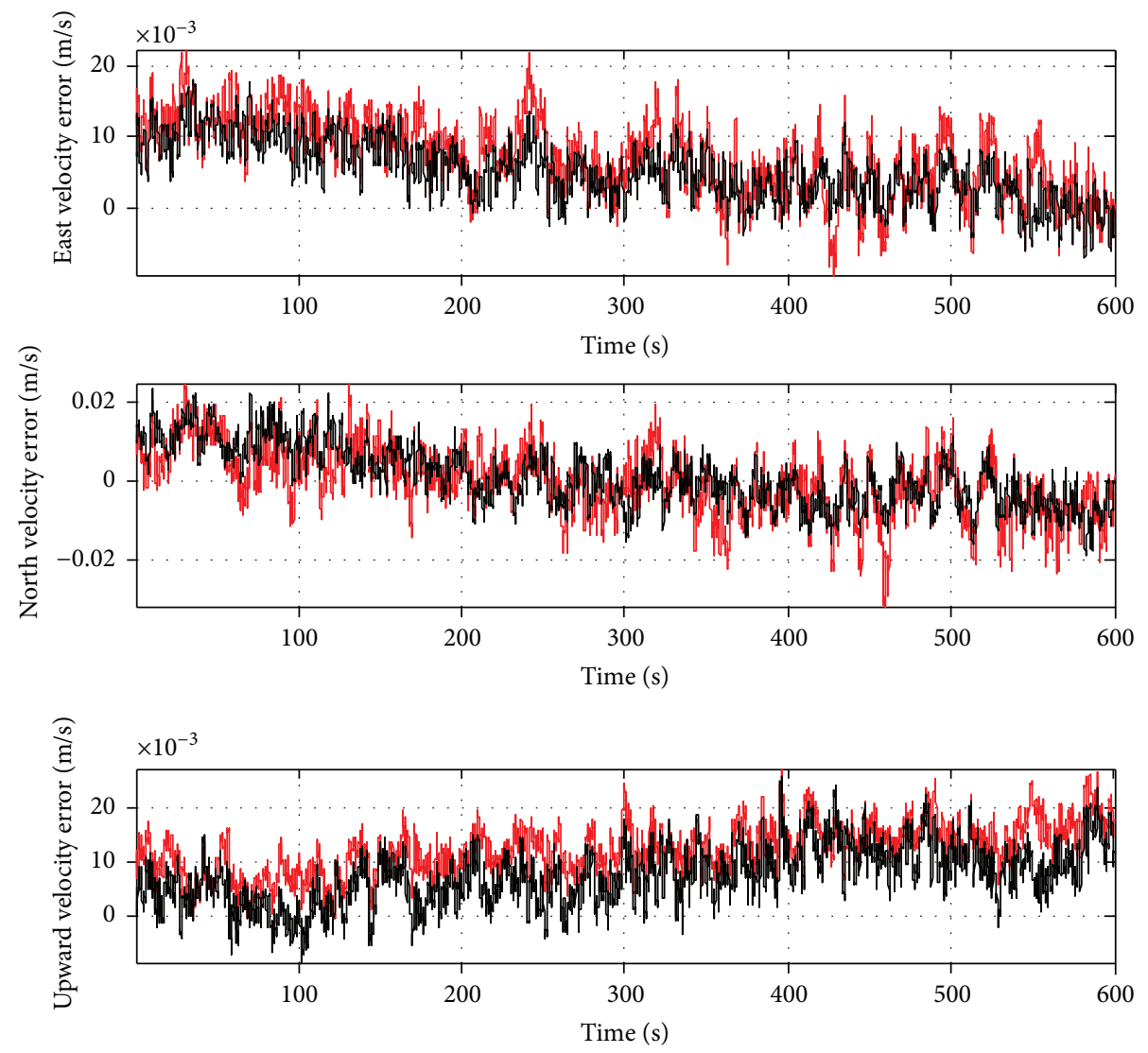

With rigid lever arm compensation

With dynamic lever arm compensation

Figure 8: Velocity error comparison of the first-level dynamic lever arm error compensation.
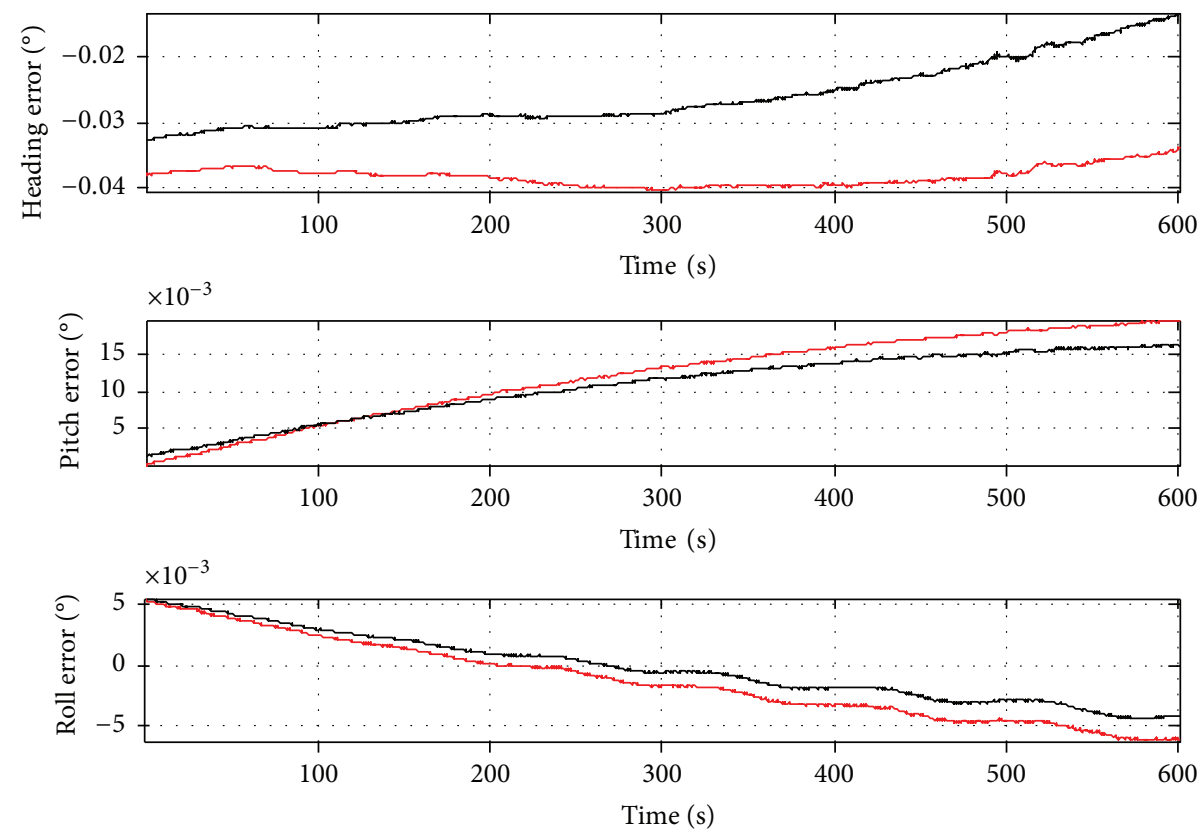

- With rigid lever arm compensation

— With dynamic lever arm compensation

Figure 9: Attitude error comparison of the first-level dynamic lever arm error compensation. 
where $\dot{\boldsymbol{\sigma}}^{\mathrm{b}}(t)$ and $\boldsymbol{\omega}_{\mathrm{nb}}^{\mathrm{b}}(t)$ can be calculated by (22) and (5), respectively.

With the velocity compensation, the velocity vector $\mathbf{V}_{\mathrm{p}}^{\mathrm{n}}(t)$ measured by POS can be transferred to the measuring center of the remote sensing load in the $\mathrm{n}$ frame, which can be expressed as

$$
\mathbf{V}_{\mathrm{sp}}^{\mathrm{n}}(t)=\mathbf{V}_{\mathrm{p}}^{\mathrm{n}}(t)+\delta \mathbf{V}_{\mathrm{IId}}^{\mathrm{n}}(t) .
$$

3.2.3. Attitude Error Modeling and Compensation. Because of the installation error angle and the rotation of the remote sensing load, the attitude of POS cannot be directly used for the remote sensing load. The transformation matrix $\mathbf{C}_{\mathrm{s}}^{\mathrm{n}}(t)$ from the s frame to the $\mathrm{n}$ frame at moment $t$ can be calculated as

$$
\begin{aligned}
\mathbf{C}_{\mathrm{s}}^{\mathrm{n}}(t) & =\mathbf{C}_{\mathrm{b}}^{\mathrm{n}}(t) \mathbf{C}_{\mathrm{R}_{0}}^{\mathrm{b}}(t) \mathbf{C}_{\mathrm{R}}^{\mathrm{R}_{0}}(t) \mathbf{C}_{\mathrm{s}}^{\mathrm{R}}(t) \\
& =\mathbf{C}_{\mathrm{b}}^{\mathrm{n}}(t) \mathbf{C}_{\mathrm{R}_{0}}^{\mathrm{b}}\left(t_{0}\right)\left[\mathbf{C}_{\mathrm{R}}^{\mathrm{R}_{0}}(t)\right]^{-1} \mathbf{C}_{\mathrm{s}}^{\mathrm{R}_{0}}\left(t_{0}\right),
\end{aligned}
$$

where $\mathrm{C}_{\mathrm{R}}^{\mathrm{R}_{0}}(t)$ can be calculated by (15). Using the attitude matrix $\mathbf{C}_{\mathrm{s}}^{\mathrm{n}}(t)$ of the remote sensing load, the heading, pitch, and roll of the remote sensing load can be calculated.

\section{Experiment and Analysis}

To validate the effectiveness, the proposed dynamic lever arm error compensation method is applied to two actual airborne SAR imaging experiments which contain the firstlevel dynamic lever arm and the second-level dynamic lever arm, respectively.

4.1. Hardware Configuration. For the first-level dynamic lever arm error compensation, the flight experiment equipment includes an experiment plane (YUN-VIII), SAR, servo machines, and the ring laser gyroscope (RLG) POS which consists of an RLG IMU, POS computer system, and carrier phase differential GPS. The RLG IMU consists of three ring laser gyroscopes with constant and random drifts $\left(0.01^{\circ} / \mathrm{h}\right)$ and quartz mechanical accelerometers with constant and random biases $(50 \mu \mathrm{g})$ assembled in orthogonal triads. The RLG IMU is fixed on the back of the SAR antenna and can be driven to sweep by the servo machine. The experiment was carried out for SAR in Shaanxi Province, China, in April 2017, and the flight trajectory is shown in Figure 4.

For the second-level dynamic lever arm error compensation, the flight experiment equipment includes an experiment plane (YUN-VII), SAR, servo machines, and the fiber optic gyroscope (FOG) POS which consists of a FOG IMU, PCS, and carrier phase differential GPS. The FOG IMU consists of three fiber optic gyroscopes with constant and random drifts $\left(0.01^{\circ} / \mathrm{h}\right)$ and quartz mechanical accelerometers with constant and random biases $(50 \mu \mathrm{g})$ assembled in orthogonal triads. The FOG POS is fixed on the plane, while the SAR antenna is installed on the servo machine and can be driven to sweep along the rotary axis. The experiment was carried out for SAR in Shaanxi Province, China, in March 2016, and the flight trajectory is shown in Figure 5.

\begin{tabular}{|c|c|c|c|}
\hline \multirow{2}{*}{\multicolumn{2}{|c|}{$\begin{array}{l}\text { Parameters measured } \\
\text { by the main POS }\end{array}$}} & \multicolumn{2}{|c|}{ The measurement error (RMSE) } \\
\hline & & $\begin{array}{l}\text { Conventional rigid } \\
\text { lever arm error }\end{array}$ & $\begin{array}{l}\text { Proposed dynamic } \\
\text { lever arm error }\end{array}$ \\
\hline \multirow{3}{*}{$\begin{array}{l}\text { Position } \\
(\mathrm{m})\end{array}$} & Latitude & 0.9377 & 0.0348 \\
\hline & Longitude & 2.0680 & 0.0259 \\
\hline & Height & 2.4657 & 0.0800 \\
\hline \multirow{3}{*}{$\begin{array}{l}\text { Velocity } \\
(\mathrm{m} / \mathrm{s})\end{array}$} & $\begin{array}{c}\text { East } \\
\text { velocity }\end{array}$ & 0.0089 & 0.0067 \\
\hline & $\begin{array}{c}\text { North } \\
\text { velocity }\end{array}$ & 0.0085 & 0.0077 \\
\hline & $\begin{array}{l}\text { Upward } \\
\text { velocity }\end{array}$ & 0.0131 & 0.0091 \\
\hline \multirow{3}{*}{ Attitude $\left({ }^{\circ}\right)$} & Heading & 0.0382 & 0.0266 \\
\hline & Pitch & 0.0132 & 0.0115 \\
\hline & Roll & 0.0034 & 0.0027 \\
\hline
\end{tabular}

TABLE 3: Measurement error comparison of the first-level dynamic lever arm error compensation.

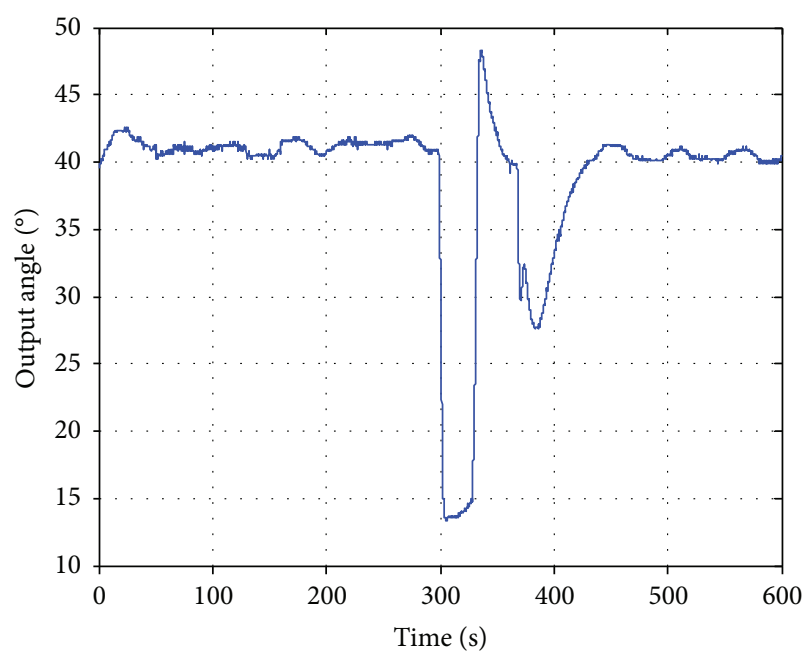

FIGURE 10: The output angles of the photoelectric encoder used in the experiment system in Figure 5.

A reference GPS receiver is set up on the ground within $100 \mathrm{~km}$ and takes a real-time radio link to the roving GNSS receiver. The GPS can achieve carrier phase difference by combining the phase data from roving and reference receivers. The real-time kinematic precision is typically $1 \sim 2 \mathrm{~cm}$ plus $1 \mathrm{ppm}$ of baseline separation.

4.2. Initial Calibration. The laser total station is an optimal instrument and can be used to calibrate the initial lever arms and transformation matrix among sensors. The measurement precision can reach submillimeter level, which is beyond the measurement precision of POS. So the calibration errors can be ignored. The initial calibration result is obtained in Tables 1 and 2.

4.3. Result and Analysis. Two groups of 10-minute experiment data are processed and analyzed for the first-level 

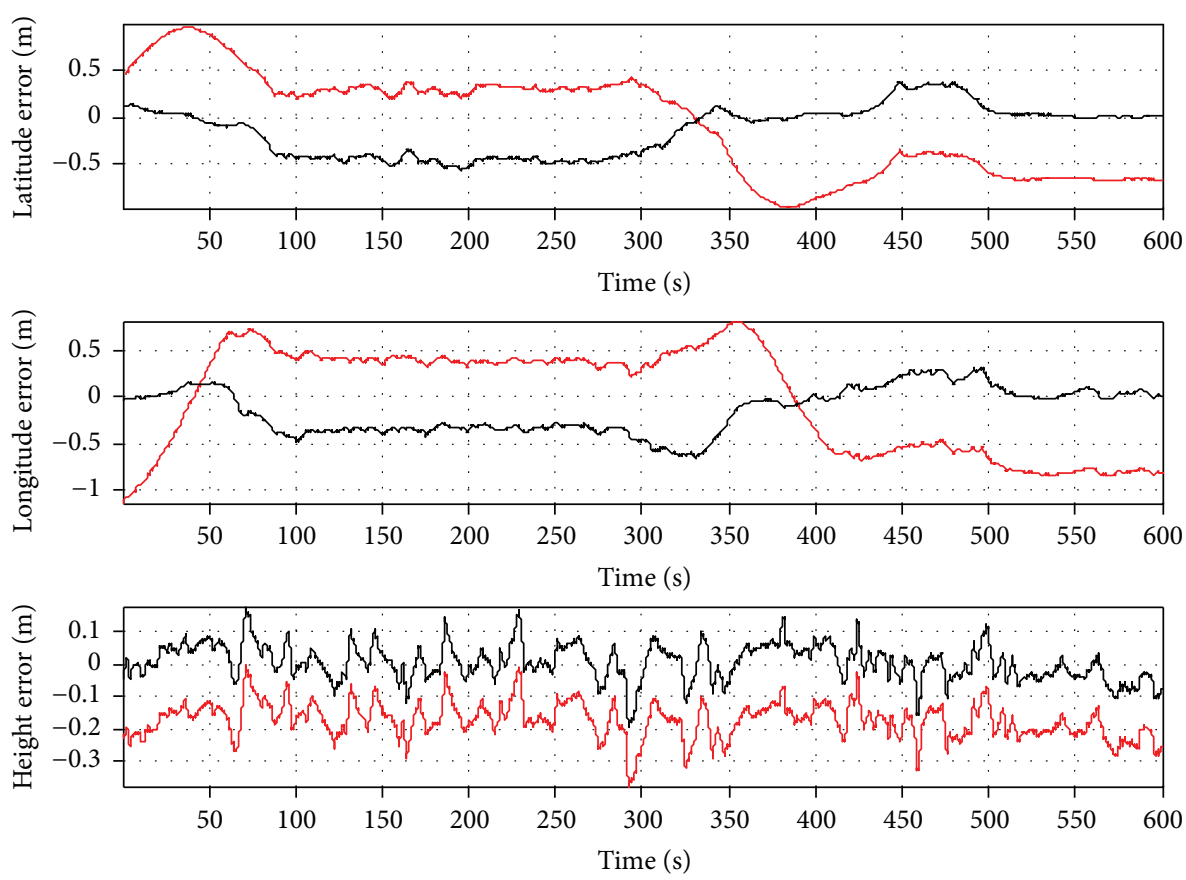

With rigid lever arm compensation
With dynamic lever arm compensation

Figure 11: Position error comparison of the second-level dynamic lever arm error compensation.

dynamic lever arm error compensation of the experiment system in Figure 4 and the second-level dynamic lever arm error compensation of the experiment system in Figure 5, respectively. The postprocessed result with the dynamic lever arm error compensation is chosen as the reference, because of its dramatic measurement accuracy provided by forward and reverse in time processing.

4.3.1. First-Level Dynamic Lever Arm Error Compensation Result. For the first-level dynamic lever arm error compensation of the experiment system in Figure 4, two experiment results are obtained. One adopts the proposed method, while the other considers the first-level dynamic lever arm a rigid one. The output angles of the photoelectric encoder used in the experiment system in Figure 4 are shown in Figure 6, from which we can learn that the dynamic change of the first-level lever arm is relatively small during the period.

The errors of RLG POS in Figure 4 calculated by the realtime Kalman filtering method with the proposed lever arm error compensation method and the conventional rigid lever arm error compensation method are shown in Figures 7-9 and Table 3.

With the proposed first-level dynamic lever arm error compensation, the latitude, longitude, and height errors have been reduced from $0.9377 \mathrm{~m}, 2.0680 \mathrm{~m}$, and $2.4657 \mathrm{~m}$ to $0.0348 \mathrm{~m}, 0.0259 \mathrm{~m}$, and $0.0800 \mathrm{~m}$, respectively. The east, north, and upward velocity errors have been reduced from $0.0089 \mathrm{~m} / \mathrm{s}, \quad 0.0085 \mathrm{~m} / \mathrm{s}$, and $0.0131 \mathrm{~m} / \mathrm{s}$ to $0.0067 \mathrm{~m} / \mathrm{s}$, $0.0077 \mathrm{~m} / \mathrm{s}$, and $0.0091 \mathrm{~m} / \mathrm{s}$, respectively. The heading, pitch, and roll angle errors have been reduced from $0.0382^{\circ}, 0.0132^{\circ}$, and $0.0034^{\circ}$ to $0.0266^{\circ}, 0.0115^{\circ}$, and $0.0027^{\circ}$, respectively.
Remark 3. The position accuracy is significantly improved by the proposed method, because the length of the first-level lever arm is long and the output angle is quite different from the initial angle. However, the improvements of velocity and attitude accuracy are small, because the servo was controlled to keep stable in the survey phase, and the influence of the dynamic lever arm effect on velocity and attitude is little.

\subsubsection{Second-Level Dynamic Lever Arm Error Compensation}

Result. For the second-level dynamic lever arm error compensation of the experiment system in Figure 5, two experiment results are obtained. One adopts the proposed method, while the other considers the second-level dynamic lever arm a rigid one. The output angles of the photoelectric encoder used in the experiment system in Figure 5 are shown in Figure 10, from which we can learn that the servo made a greatly adjustment during $300 \mathrm{~s}-450 \mathrm{~s}$.

The errors of FOG POS in Figure 5 calculated by the realtime Kalman filtering method with the proposed lever arm error compensation method and the conventional rigid lever arm error compensation method are shown in Figures 11-13 and Table 4.

With the proposed first-level dynamic lever arm error compensation, the latitude, longitude, and height errors have been reduced from $0.5470 \mathrm{~m}, 0.5738 \mathrm{~m}$, and $0.1816 \mathrm{~m}$ to $0.2921 \mathrm{~m}, 0.2805 \mathrm{~m}$, and $0.0544 \mathrm{~m}$, respectively. The east, north, and upward velocity errors have been reduced from $0.0230 \mathrm{~m} / \mathrm{s}, \quad 0.0283 \mathrm{~m} / \mathrm{s}$, and $0.0140 \mathrm{~m} / \mathrm{s}$ to $0.0210 \mathrm{~m} / \mathrm{s}$, $0.0255 \mathrm{~m} / \mathrm{s}$, and $0.0132 \mathrm{~m} / \mathrm{s}$, respectively. The heading, pitch, and roll angle errors have been reduced from $0.0530^{\circ}, 0.1224^{\circ}$, and $7.0999^{\circ}$ to $0.0221^{\circ}, 0.0062^{\circ}$, and $0.0045^{\circ}$, respectively. 

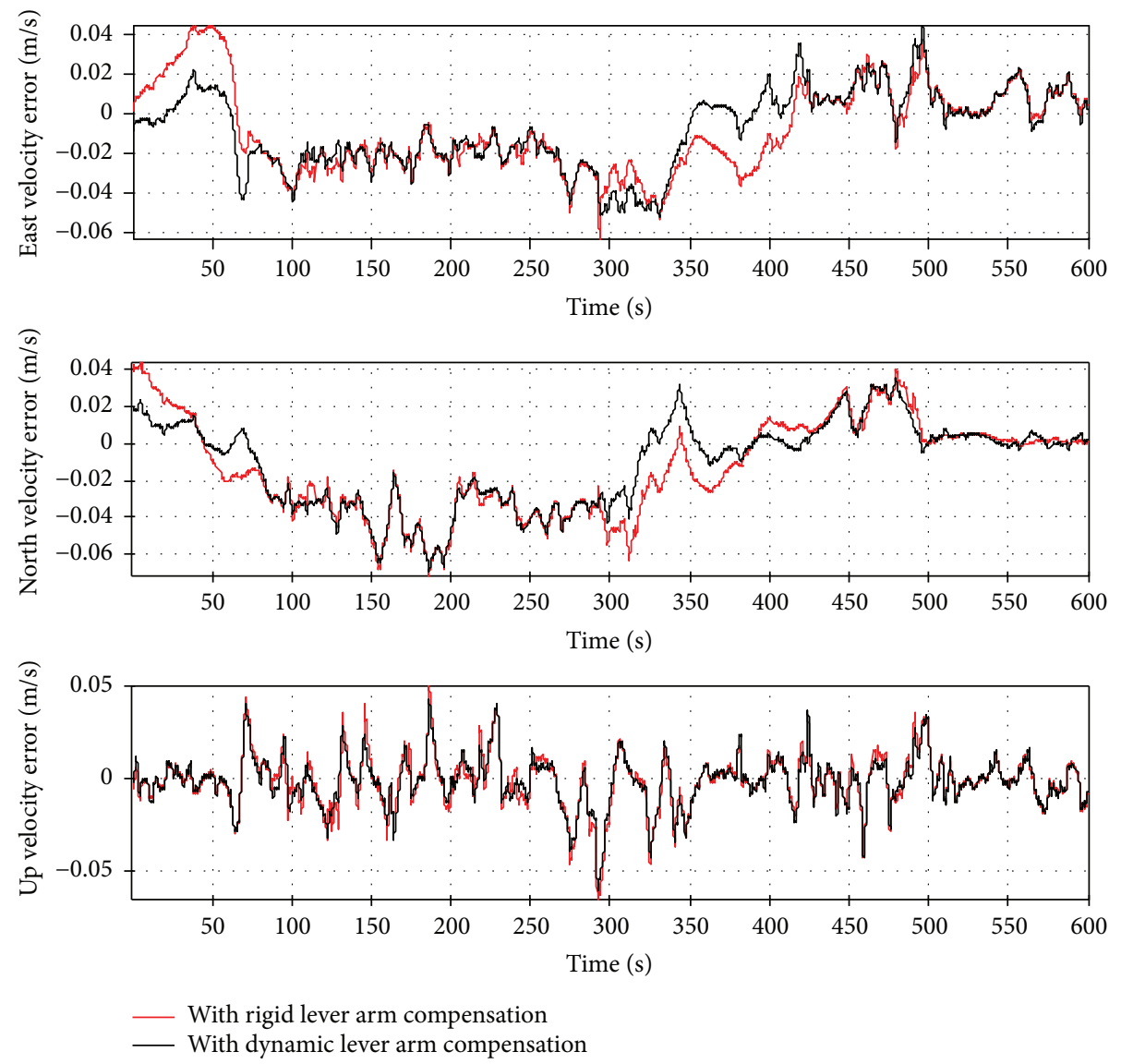

FIGURE 12: Velocity error comparison of the second-level dynamic lever arm error compensation.
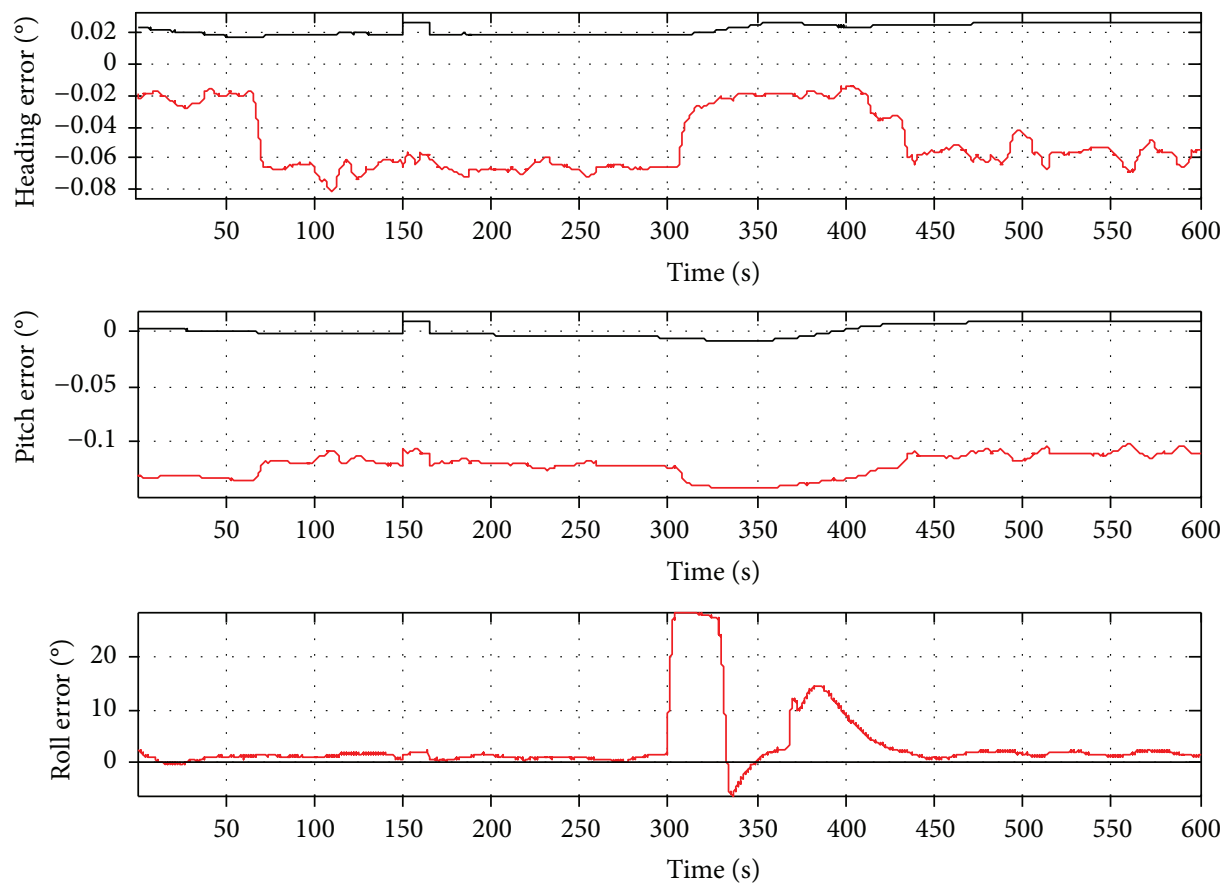

With rigid lever arm compensation

With dynamic lever arm compensation

Figure 13: Attitude error comparison of the second-level dynamic lever arm error compensation. 
TABLE 4: Measurement error comparison of the second-level dynamic lever arm error compensation.

\begin{tabular}{|c|c|c|c|}
\hline \multirow{2}{*}{\multicolumn{2}{|c|}{$\begin{array}{l}\text { Parameters } \\
\text { measured by the } \\
\text { main POS }\end{array}$}} & \multicolumn{2}{|c|}{ The measurement error (RMSE) } \\
\hline & & $\begin{array}{l}\text { Conventional rigid } \\
\text { lever arm error } \\
\text { compensation }\end{array}$ & $\begin{array}{l}\text { Proposed dynamic } \\
\text { lever arm error } \\
\text { compensation }\end{array}$ \\
\hline \multirow{3}{*}{$\begin{array}{l}\text { Position } \\
\text { (m) }\end{array}$} & Latitude & 0.5470 & 0.2921 \\
\hline & Longitude & 0.5738 & 0.2805 \\
\hline & Height & 0.1816 & 0.0544 \\
\hline \multirow{3}{*}{$\begin{array}{l}\text { Velocity } \\
(\mathrm{m} / \mathrm{s})\end{array}$} & $\begin{array}{c}\text { East } \\
\text { velocity }\end{array}$ & 0.0230 & 0.0210 \\
\hline & $\begin{array}{l}\text { North } \\
\text { velocity }\end{array}$ & 0.0283 & 0.0255 \\
\hline & $\begin{array}{l}\text { Upward } \\
\text { velocity }\end{array}$ & 0.0140 & 0.0132 \\
\hline \multirow{3}{*}{$\begin{array}{l}\text { Attitude } \\
\left({ }^{\circ}\right)\end{array}$} & Heading & 0.0530 & 0.0221 \\
\hline & Pitch & 0.1224 & 0.0062 \\
\hline & Roll & 7.0999 & 0.0045 \\
\hline
\end{tabular}

Remark 4. The attitude accuracy is significantly improved by the proposed method, because the SAR is not fixed on IMU, and the attitude error will be insufferable without dynamic compensation. However, the improvements of position and velocity accuracy are small, because the length of second dynamic lever arm is short, and the influence of the dynamic lever arm effect on position and velocity is little.

Above all, it is validated that the proposed dynamic lever arm error compensation method can effectively compensate the dynamic lever arm error and achieve higher accuracy and more extensive application for airborne POS.

\section{Conclusion}

The dynamic lever arm error compensation method of POS used for airborne Earth observation has been proposed in this paper. Firstly, the conventional rigid lever arm error compensation method is presented. Secondly, the first-level and the second-level dynamic lever arm error compensation methods are derived in detail, respectively. Finally, two actual flight experiments are carried out to validate the proposed method, which include both the first-level and the secondlevel dynamic lever arm error compensations. The results show that the derived dynamic lever arm compensation method outperforms the conventional one. Therefore, the proposed dynamic lever arm error compensation method can effectively compensate the dynamic lever arm error and achieve higher accuracy and more extensive application for airborne POS.

\section{Conflicts of Interest}

The authors declare that they have no conflicts of interest.

\section{Acknowledgments}

This work was supported in part by the National High Technology Research and Development Program of China (863 Program) (2015AA124001, 2015AA124002), in part by the China National Natural Science Foundation (61421063, 61571030,61573040 , and 61473020), in part by the International (Regional) Cooperation and Communication Project (61661136007), and in part by the Basic Scientific Research (YWF-17-BJ-Y-71).

\section{References}

[1] M. Herold, C. E. Woodcock, T. R. Loveland et al., "Land-cover observations as part of a Global Earth Observation System of Systems (GEOSS): progress, activities, and prospects," IEEE Systems Journal, vol. 2, no. 3, pp. 414-423, 2008.

[2] K. Tan and W. Li, "Imaging and parameter estimating for fast moving targets in airborne SAR," IEEE Transactions on Computational Imaging, vol. 3, no. 1, pp. 126-140, 2017.

[3] M. M. R. Mostafa and J. Hutton, "Direct positioning and orientation systems: how do they work? What is the attainable accuracy," in Proceedings, The American Society of photogrammetry and remote sensing annual meeting, St. Louis, MO, USA, April 2001.

[4] Y. Zhang, X. Xiong, M. Zheng, and X. Huang, "LiDAR strip adjustment using multifeatures matched with aerial images," IEEE Transactions on Geoscience and Remote Sensing, vol. 53, no. 2, pp. 976-987, 2015.

[5] J. Fang and Z. Liu, "In-flight alignment of POS based on statetransition matrix," IEEE Sensors Journal, vol. 15, no. 6, pp. 3258-3264, 2015.

[6] Q. Cao, M. Zhong, and J. Li, "On analytical error analysis of POS for ground alignment and constant-velocity flight," IEEE Transactions on Instrumentation and Measurement, vol. 65, no. 9, pp. 2154-2162, 2016.

[7] J. Fang, L. Chen, and J. Yao, "An accurate gravity compensation method for high-precision airborne POS," IEEE Transactions on Geoscience and Remote Sensing, vol. 52, no. 8, pp. 4564-4573, 2014.

[8] Y. Geng, R. Deurloo, and L. Bastos, "Hybrid derivative-free extended Kalman filter for unknown lever arm estimation in tightly coupled DGPS/INS integration," GPS Solutions, vol. 15, no. 2, pp. 181-191, 2011.

[9] J. Dickman and C. Bartone, "Considerations for sensor stabilization using stand-alone GPS velocity and inertial measurements," in 2007 IEEE Aerospace Conference, pp. 1-16, Big Sky, MT, USA, March 2007.

[10] J. Farrell and M. Barth, The Global Positioning System and Inertial Navigation, McGraw-Hill Professional, New York, NY, USA, 1999.

[11] Y. Ma, F. Jiancheng, and C. Junchao, "The model of multi-level lever-arm in position and orientation system," in 2012 8th IEEE International Symposium on Instrumentation and Control Technology (ISICT) Proceedings, pp. 183-188, London, UK, July 2012.

[12] S. Hong, M. H. Lee, H.-H. Chun, S.-H. Kwon, and J. L. Speyer, "Observability of error states in GPS/INS integration," IEEE Transactions on Vehicular Technology, vol. 54, no. 2, pp. 731-743, 2005. 
[13] S. Hong, M. H. Lee, H.-H. Chun, S.-H. Kwon, and J. L. Speyer, "Experimental study on the estimation of lever arm in GPS/ INS," IEEE Transactions on Vehicular Technology, vol. 55, no. 2, pp. 431-448, 2006.

[14] Y. Ma, J. Fang, and J. Li, "Accurate estimation of lever arm in SINS/GPS integration by smoothing methods," Measurement, vol. 48, pp. 119-127, 2014.

[15] J. Seo, H. K. Lee, J. G. Lee, and C. G. Park, "Lever arm compensation for GPS/INS/odometer integrated system," International Journal of Control, Automation, and Systems, vol. 4, no. 2, pp. 247-254, 2006.

[16] W. Jiang, Y. Li, and C. Rizos, "On-the-fly Locata/inertial navigation system integration for precise maritime application," Measurement Science and Technology, vol. 24, no. 10, p. 105104, 2013.

[17] Y. Lu and X. Cheng, "Random misalignment and lever arm vector online estimation in shipborne aircraft transfer alignment," Measurement, vol. 47, pp. 756-764, 2014.

[18] J. Cheng, T. Wang, N. Dong, Y. Kang, and G. Jiang, "On leverarm effect compensation for polar transfer alignment," in 2016 35th Chinese Control Conference (CCC), pp. 5569-5574, Chengdu, China, July 2016.

[19] X. Liu, X. Xu, L. Wang, Y. Li, and Y. Liu, " $H_{\infty}$ filter for flexure deformation and lever arm effect compensation in M/S INS integration," International Journal of Naval Architecture and Ocean Engineering, vol. 6, no. 3, pp. 626-637, 2014.

[20] Q. Cao, M. Zhong, and Y. Zhao, "Dynamic lever arm compensation of SINS/GPS integrated system for aerial mapping," Measurement, vol. 60, pp. 39-49, 2015.

[21] M. Zhong, Q. Cao, J. Guo, and D. Zhou, "Simultaneous leverarm compensation and disturbance attenuation of POS for a UAV surveying system," IEEE Transactions on Instrumentation and Measurement, vol. 65, no. 12, pp. 2828-2839, 2016. 


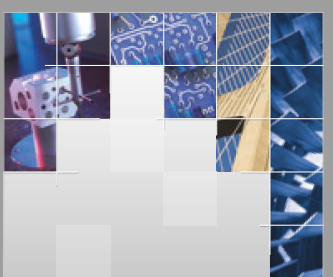

\section{Enfincering}
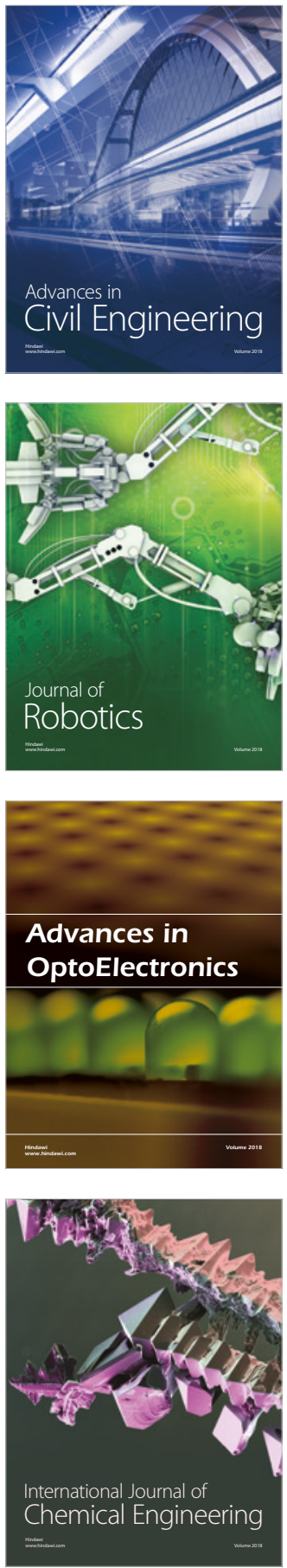

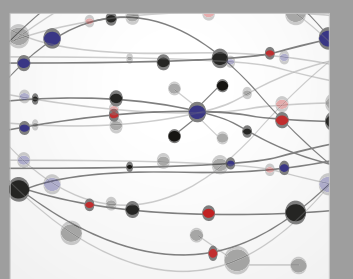

\section{Rotating \\ Machinery}

The Scientific World Journal

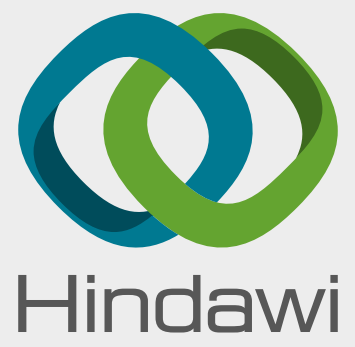

Submit your manuscripts at

www.hindawi.com
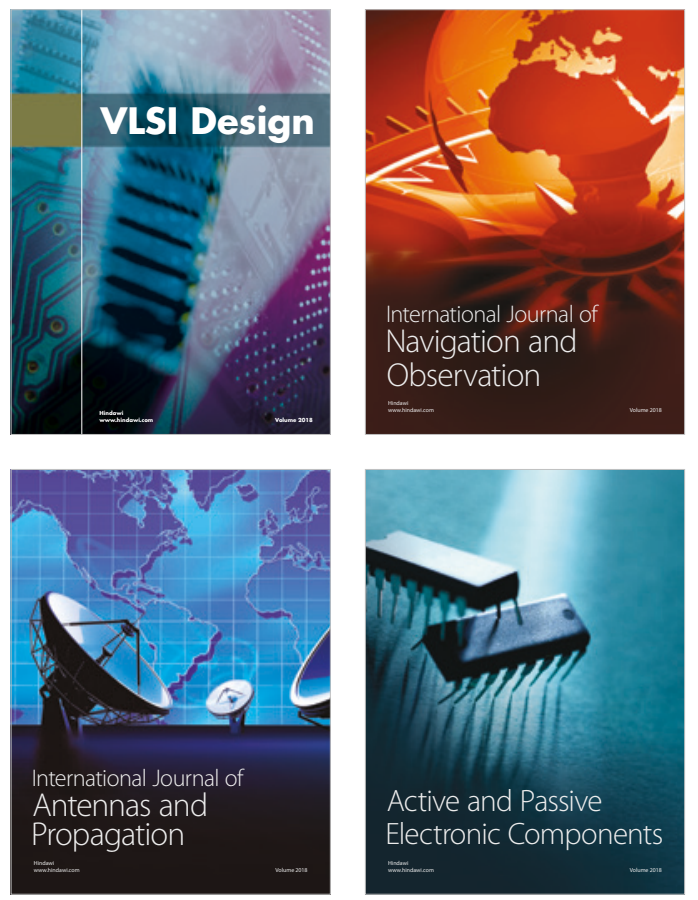
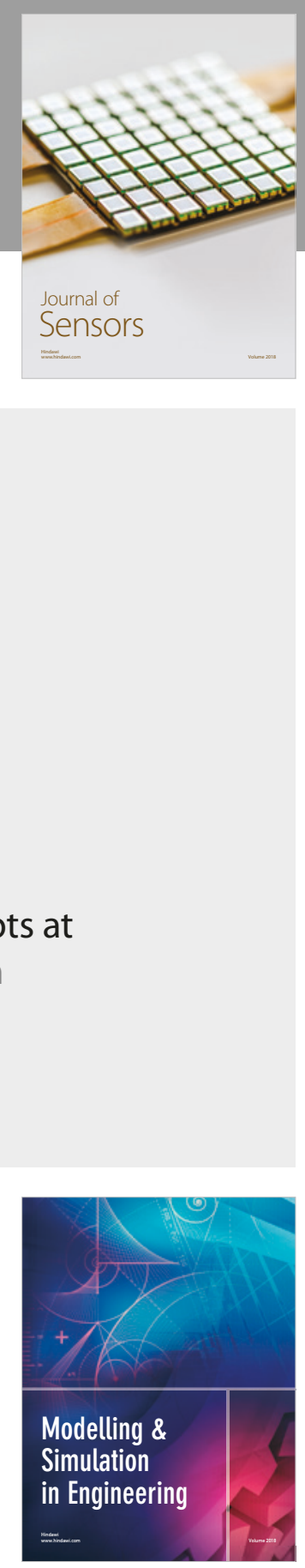

\section{Advances \\ Multimedia}
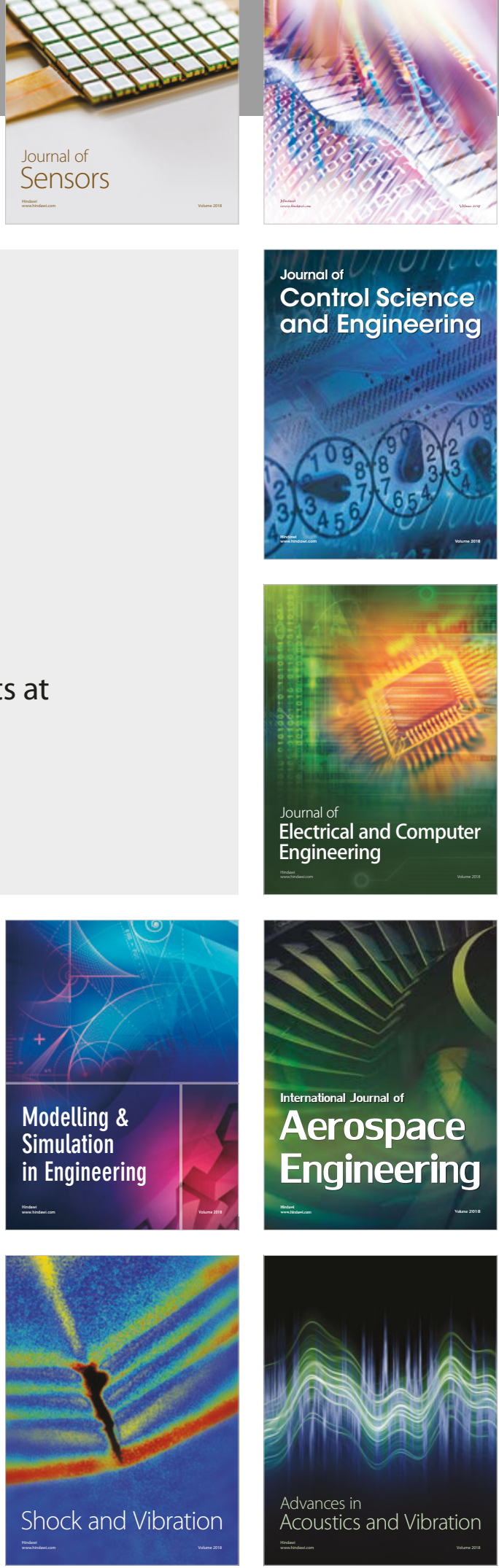